\title{
Papers
}

\section{Management of major trauma: changes required for improvement}

\author{
J Dyas, P Ayres, M Airey, J Connelly
}

\begin{abstract}
Aims-To describe the views of key healthcare professionals on the changes they considered to be important in the reduction of major trauma mortality between 1988 and 1995 in Leeds.

Methods-Qualitative unstructured interviews with a purposive sample of 10 healthcare professionals deemed to be key personnel by an experienced consultant who had provided acute trauma care throughout the relevant period. Each interview was tape recorded and transcribed; each transcript was analysed for important themes by two independent researchers who then discussed their results to resolve any differences in interpretation.
\end{abstract}

Results-Three categories of change became evident: "policy", "infrastructure", and "philosophy of care". Each of these categories seemed to be equally important. Policy changes identified as important were the Royal College of Surgeons of England's report into trauma care (1988), the setting of standards for paramedic training, and the national audit of major trauma outcomes. Important infrastructure changes identified were training in advanced trauma life support, decreased ambulance response times, reorganisation towards "consultant led" hospital services, and an emphasis on quality monitoring. Changes in philosophy of care were increases in levels of teamwork, commitment, communication, and confidence. Together these facilitated an overall restructuring and refocusing of care.

Conclusions-No individual change is seen as dominant for improved care, but rather a strategic mixture of facilitating national and regional policy guidance, organisational restructuring, and congruent professional attitudes were integral components leading to the observed changes. Improving outcomes in other areas is likely to involve an integrated series of changes which must be managed as a total system.

(Quality in Health Care 1999;8:78-85)

Keywords: trauma; change management
Traumatic injury is acknowledged as a major cause of death and disability on a global scale. Even with the advent of HIV related illness, accidental injury has been described as probably being the most serious of all epidemics facing mankind in the developed countries. ${ }^{1}$ Infectious disease is now outranked as a cause of death by injury in the middle income nations in Latin America ${ }^{2}$ and Asia. ${ }^{3}$ Trauma is also the leading cause of death in patients under the age of 37 years in the United States and accounts for more deaths than all other diseases combined. ${ }^{4}$

In the UK there are around 14000 deaths each year as a result of trauma. ${ }^{5}$ Trauma care has received attention from both researchers and policy makers in efforts aimed at improving outcome after severe injury. These efforts have been most recently stimulated by the influential 1988 report published by the Royal College of Surgeons of England and the 1992 report from the British Orthopaedic Association. ${ }^{16}$ The Royal College of Surgeons' report was based on evidence from a retrospective study in which 1000 hospital deaths from trauma were studied. The results suggested that up to a third of these could be avoided through the provision of optimal care. ${ }^{7}$ The report made several key recommendations aimed at improving the management of patient with major injuries (box 1).

Governmental recognition of the importance of this area led to its incorporation in the 1992 Health of the Nation which gave the target of reducing deaths from injury by one quarter within five years of its publication. ${ }^{8}$ The most recent government health policy document, Our Healthier Nation, ${ }^{9}$ reiterates and expands on this aspiration and seeks to reduce fatal and non-fatal accidents by at least one fifth by 2010 from a baseline in 1996 .

In an attempt to qualify the attainability of such targets we have, in previous work, compared the survival outcomes of major trauma patients identified for a 12 month period, September 1988 to October $1989,{ }^{10}$ with those patients admitted to the same hospitals four years later. This study examined mortality data on patients treated at the two hospitals in Leeds which have designated accident and emergency facilities (Leeds General Infirmary and St James' University Hospital). ${ }^{11}$ 


\section{Pre-hospital care}

Extend training of ambulance crews to "paramedic" status, improve communication links, explore other patient transport methods (helicopter).

\section{Hospital care}

Only one designated accident and emergency department for each health district, establish second tier of hospital care (regional trauma centres).

\section{Facilities and staffing}

Increase consultant posts in emergency medicine, consultant led resuscitation.

\section{Surgical training}

Adopt team approach, advanced trauma life support (ATLS) training, encourage other specialty involvement in accident services.

\section{Audit and quality control}

Establish UK major trauma outcome study.

\section{Research on trauma in the UK} Increase funding.

Box 1 Key recommendations of 1988 Royal College of Surgeons' report into the management of patients with major injuries ${ }^{1}$

Major trauma was defined as an injury severity score of 16 and greater. ${ }^{12}$ The significant improvements (box 2) in observed mortality outcome suggests that the Our Healthier Nation target for mortality is achievable. More recently, a report from the UK's major trauma outcome study group has shown similar reductions in accidental death rates in children and young adults, ${ }^{13}$ thus strengthening this conclusion. Both reports hint at mechanisms by which the observed reductions have come about, ${ }^{11}{ }^{13}$ but these are not fully defined or explored. Since the pivotal 1988 Royal College of Surgeons' report, interacting factors, both medical and organisational, have been put into place which may have been responsible for this observed improvement in major trauma outcome.

The mortality outcomes of 186 patients with major trauma (with an injury severity score of >15) admitted to the two Leeds hospitals in 1988-9 were compared with the 198 patients admitted to the same hospitals in 1992-3:

- Injury severity score, injury type, age and sex distributions were similar for the two groups.

- There were significantly fewer deaths in 1992-3 (47 v 90)

- Relative risk of dying in 1992-3 compared with 1998-9 was 0.68, 95\% confidence interval (0.58 to 0.79 )

These results suggest that changes in the management of patients with major trauma in Leeds since 1988 have led to improved survival for seriously injured patients.

Box 2 Summary of observed mortality outcome
Consultant medical staff involved in trauma care (Consultant)

Accident and emergency $(n=2)$

Cardiothoracic surgery $(n=1)$

Plastics and reconstructive surgery $(n=1)$

Rehabilitation medicine $(\mathrm{n}=1)$

Skeletal trauma $(\mathrm{n}=1)$

Orthopaedics $(n=1)$

Trauma nurse $(\mathrm{n}=1)$ (Nurse)

Yorkshire regional staff $(n=1)$ (Region)

Ambulance service staff $(n=1)$ (Ambulance)

Box 3 Professional background of informants

Change in processes and the behaviour of teams of people and of organisations is complex. Much can be learnt, however, from attempting to describe and understand a process of change that resulted in a successful outcome. Rather than leaving the details of the changes which occurred in services supplying major trauma care in Leeds as the contents of a "black box" therefore, the aim of the present study was to open the box and describe the complex picture of organisational change which led to alterations in the approach to the care of the critically injured.

\section{Methods}

The research design was qualitative. Unstructured interviews ${ }^{14}$ were conducted early in 1996 with 10 healthcare professionals involved in different aspects of major trauma services in Leeds. This method was used so that discussions were not confined to issues raised by the researchers. This proved to be particularly important because the "key informant" (see below) had described a complex series of changes in major trauma care management during this period. Use of an unstructured approach allowed scope for the identification of salient issues.

\section{SELECTION OF INTERVIEWEES}

The informants approached for interview were selected after a process of consultation between the authors and one local consultant (the key informant) who had been involved in providing trauma care in Leeds throughout the study period. The key informant was interviewed by two of the authors (PA and MA) who made written notes of the broad nature of the issues to be addressed and actively engaged in conversation about the respondents who were to be approached for interview. Interviewees were selected purposively ${ }^{15}$ to ensure representation from a wide range of different disciplines involved in the delivery or organisation of major trauma care in Leeds. Efforts were made to ensure that interviewees had been working in the area over the time period studied. Box 3 lists the professional backgrounds of the people interviewed. The professional categories shown are deliberately vague to preserve anonymity.

\section{INTERVIEWS}

Each respondent was interviewed individually by one of the authors. The interview was conducted in the place of the respondents choice 


\section{(1) Policy}

- Publication of the Royal College of Surgeons' report on major trauma

- Regional process of consultation

- Major trauma outcome survey

- NHS Management Executive (NHSME) set standards for paramedic training

(2) Infrastructure changes

- Training: specifically ATLS and paramedic

- Ambulance service reorganisation

- Reorganisation of hospital trauma services

- Monitoring quality: audit

(3) Change in philosophy of care

- Commitment

- Attitudinal changes

- Confidence

- Teamwork and communication

Box 4 Factors considered important in the reduction of mortality from major trauma

(usually their office) to facilitate disclosure. All interviews were recorded on audio tape and were fully transcribed, the length of the interviews ranged from 20 minutes to 45 minutes. Prompts were occasionally used to encourage the respondents to explain a point in more detail. The interviewers (JD, PA, and MA) were from different professional backgrounds (nursing, medicine, and trauma research, respectively). These were, where possible, matched with the background of the respondents. This was expected to help to capture a greater diversity of response. None of the authors has had any direct involvement in trauma services.

ANALYSIS

The aim of the analysis was to identify key components in the improvement of major trauma services and to assess how these various components related to each other. There was no intention to quantify the responses numerically. The content of the transcripts were analysed generating themes and categories. The thematic analyses were conducted independently by two of the authors (JD and PA). Triangulation ${ }^{15}$ of these independent analyses revealed no real difference in interpretation of the content of the interviews.

\section{Results}

Respondents provided most information about the parts of the process in which they were directly involved. The elements of the black box of change in trauma care cited as important can be organised into the themes: policy, infrastructure changes, and changes in philosophy of care. Box 4 summarises the themes. To give a clear idea of when each of the changes occurred, box 5 gives a chronological explanation of the main changes, as described by respondents. More detail from the respondents is given in the text below.

\section{7}

- Very small number of trained paramedics

- No recognised system for dealing with major trauma

- No formal existence of trauma teams

- No system in place for call out of senior clinicians for major trauma

1988

- Royal College of Surgeons' report published

- Royal College of Surgeons ran first ATLS course in UK

- Major reorganisation of the ambulance service: separated emergency and outpatient services to improve response times

\section{9}

- First people in Leeds trained in ATLS

- Accident and emergency consultants in both hospitals became ATLS instructors

- Government funding for training of paramedics

1990

- Gradual introduction of trauma teams and call out system to get the team there before the patient arrived

- NHS Management Executive set standards for paramedic training: $50 \%$ to be trained paramedics by 1996

1991

- Trauma audit started using a standardised scoring system: audit clerk employed

1992

- Regional accreditation of accident and emergency departments in district general hospitals was introduced; departments were required to submit data to the major trauma outcome study; have access to emergency theatres; and have ATLS trained personnel

- Ambulance service achieved the national standard for improved response times

- Nurses started training in ATLS

- Consultants much more likely to be present for cases of major trauma

- More likely to be a fully staffed operating theatre available for emergencies

Box 5 Chronological explanation of changes described by respondents. $A T L S=$ advanced trauma life support

POLICY

The Royal College of Surgeons'report

The publication of the Royal College of Surgeons' report on major trauma services in $1988^{1}$ was described as a great stimulus for change in services dealing with major trauma. This report was frequently mentioned by respondents as being of some significant importance to the changes that subsequently took place, if only in that it focused public attention on major trauma:

“. . . it (the Royal College of Surgeons' report) started to push major trauma up the agenda and started saying to people, look you know you are not actually doing as wonderfully as you think you are doing, people are dying unnecessarily . . ."(Region) 
Several of the respondents did not agree entirely with all aspects of the report but still felt that it had been an important part of the change process:

"I have been known to be critical of the 1988 College of Surgeons' report . . but with the retrospectoscope ... they were very accurate in their recommendations to the conclusions I have reached with experience in the past few years... ." (Consultant)

Different respondents highlighted different parts of the report as being important, but the underlying emphasis was that what it said was not astounding or new but merely bringing the obvious to public attention:

"... a b c really, airway, breathing circulation, they're the things that were killing people according to the Royal College Report in 1988." (Consultant)

The Royal College of Surgeons' report was backed up in the Yorkshire region by an accreditation programme for accident and emergency departments which took place as a result of a regional consultation exercise, and this was mentioned by several respondents as being important. This occurred in 1992, towards the end of the period of study, which suggests that it was not accreditation but the process of consultation which served to raise the profile of major trauma still further.

Major trauma outcome study

During the period under review the major trauma outcome study was set up in the UK. ${ }^{16}$ This provided the means with which to measure the quality of the service. It was seen by some respondents as an important change lever in itself:

"Major trauma outcome study is a great lever. . .this is a nationally run audit system and it's a huge database... I think it is a useful tool ... I think that the one thing it does is it identifies unexpected deaths ..."'(Consultant)

Several respondents thought that the fact that it was a standardised way of collecting data was important as it made people take the data seriously and supplied a focus for multidisciplinary team meetings.

NHSME set standards for paramedic training ${ }^{17}$ Concurrent changes were occurring outside the hospital environment in the ambulance service. In 1990 specific targets were set in relation to training paramedics, which stated that there must be one paramedic on each front line ambulance at the end of six years and this would require 10 per cent of ambulance staff to be paramedic trained each year (box 6). This was described not only by the ambulance service staff but also by one of the consultant medical staff:

". . .suddenly from having four or six (paramedics) we were training a lot more and soon after, in about 1991, the NHSME said by 1996 we want half the ambulance technicians to be paramedics, and so that set a clear goal which most ambulance authorities have been able to hit." (Consultant)

This was echoed by other respondents.
- Paramedic training should be standardised and carried out at an approved regional ambulance training school

- Recommended minimum standards, for example there will be one paramedic on each front line ambulance at the end of six years

- Recommended a 50 centile response time of eight minutes for all services and a 95 centile response time of 14 and 19 minutes for urban and rural services, respectively.

- Incorporated the recommendations of the Royal College of Surgeons' report

Box 6 The modern ambulance service: good practice guidance $1990^{17}$

\section{INFRASTRUCTURE CHANGES}

The infrastructure changes described include the main practical changes that can be seen in the working environments, these have in many instances been stimulated by policy.

\section{Training}

Various aspects of training were considered to be important. The main one, mentioned by all respondents, was ATLS:

". . . at that time (1988) there was no system for dealing with trauma ... working without any system at all is a very prejudicial way to treat people ... Somebody might come in with major priorities of resuscitation . . . and the doctor may just set about it such an ad hoc way that he gets to the first priority after 20 minutes.” (Consultant)

ATLS training began to have an impact after 1988:

"I can remember myself when I started to think slightly differently... I started to realise that we were all speaking the same language and there is no apology for saying that was essentially when ATLS teaching and protocols came about." (Consultant)

This impact was not confined to the hospital setting, as described in a particular case:

"I can remember cases from pre-ATLS where... a van over turned on the A1, the driver of the van obviously had a " $C$ " spine injury and he was brought in on a scoop, face down. The spine was beautifully protected, but he wasn't breathing, so he was dead on arrival ... I don't believe (that) will ever happen again because of the advent of paramedics.” (Nurse)

\section{Ambulance service reorganisation}

In addition to the training of paramedics, other organisational changes were implemented within the ambulance service, which resulted in improved response times:

"... what we did in 1988 was to ... make all the accident and emergency services completely discreet from the outpatient services, devolved ... the local management and planning and scheduling of all the outpatient journeys down to a local level, with a control set up based at each of the nine district hospitals that we served, and then concentrated in central control, (on) managing accident and emergency response." (Ambulance)

Several respondents described the resulting reduction in response times as a major influence: 
- Systems set up to warn accident and emergency departments of major trauma patients in advance of their arrival

- Shift towards more senior medical staff present 24 hours a day for early involvement in the treatment of major trauma patients

- Increased awareness of the importance of a team approach both within the accident and emergency department and throughout the specialties dealing with major trauma

Box 7 Reorganisation of hospital trauma care

"I actually believe, but I don't have any real evidence to support it, that... the change with the most impact is the improvement in the response time... " (Consultant)

Reorganisation of hospital trauma services

Changes had also taken place within the hospitals. There had been major changes in the composition of hospital trauma teams and how they were organised (box 7).

Several consultants attributed this to the appointment of a new cohort of consultants to manage trauma. These "opinion leaders" were instrumental in developing and implementing the changes.

"There has been a huge improvement in the quality of what happens to patients very quickly in accident departments .... and I think that's because in this city we have had a generation change in consultants." (Consultant)

One consultant placed more importance on the nurses' role in the team than the availability of consultants during the night:

"...the nurse went through that course (ATLS) too and she's a staff member on that unit and she's seen it again and again and again and often that's your backbone, not your consultant at night." (Consultant)

Monitoring quality

Quality was an issue that had been addressed both within hospitals and the ambulance service. Within the hospitals, major trauma audit played a key part in maintaining and improving the quality of the service. Monthly audit meetings were held "to look at the major cases we'd had and what learning points we could extract and that run to this day" (Consultant)

These audit meeting were multidisciplinary, as explained by one specialist consultant:

"If there is a death which is related in any way to (my specialty) we are invited both to discuss the death and to criticise the management constructively." (Consultant)

The data collected for submission to major trauma outcome studies was used at the audit meetings:

"So suddenly within a two year period we were able to transform an ad hoc system into one where teams were working, where the objective data were presented monthly, and the objective data were so sophisticated compared with how it had been." (Consultant)

Ambulance service audit was fed back to the staff to foster ownership by the crews.
"We've . . .little rewards in there for improvements in standard and things like this, so there's a lot of ownership...the crews on the station will ring up the communications centre every day and ask them . . what was their response time for that." (Ambulance)

CHANGE IN PHILOSOPHY OF CARE

In addition to policy and infrastructure changes the way that individuals and clinical teams approached their work also changed. Major shifts in commitment, attitude, confidence, teamwork, and communication were considered important.

\section{Commitment}

Commitment was shown at all levels:

"The difference between then and now is that you've now got a cohort of people who are interested in the management of trauma, they think that it is something that's not done well, that can be done better.” (Consultant)

\section{Attitudinal changes}

Several respondents described changes in attitude. The availability of consultants 24 hours a day is one example; training for junior doctors is another:

"...this 'consultant led service' is like some quote in the back of some peoples mind. But it is actually real for the young guys. We will come in, you know- 'Call me when there's a problem' is a real instruction, it's not a sort of 'Call me if there's a problem and God help you if you call me': it's not that." (Consultant)

"We changed the mindset of the junior doctors that says you need to be ATLS trained and that's a vital part..."(Region)

\section{Confidence}

ATLS was most often seen as increasing confidence to do necessary invasive procedures early and to take charge of the situation:

".... you could recognise somebody who had done ATLS straightaway ... the people who had done ATLS were more prepared to take charge." (Nurse)

\section{Teamwork and communication}

Teamwork and communication were also linked to ATLS training:

"I think it (ATLS) has made such a difference to the way we work, and such a difference with patients, it's fabulous, and the consistency is great...” (Nurse)

Improved communication between the ambulance service and hospitals was felt to be important by respondents. An example given was an early warning system to notify the hospital that a patient having suffered major trauma was on their way:

"I think communication between the ambulance service and the hospitals improved in that time too, so now the hospital is much more likely to be expecting and be set up for a patient coming with significant trauma." (Consultant)

A complex picture has emerged which involves many different professional groups, high quality communication, and a common agenda or aspiration which everyone is working towards. Figure 1 summarises these various components and the links between them. 


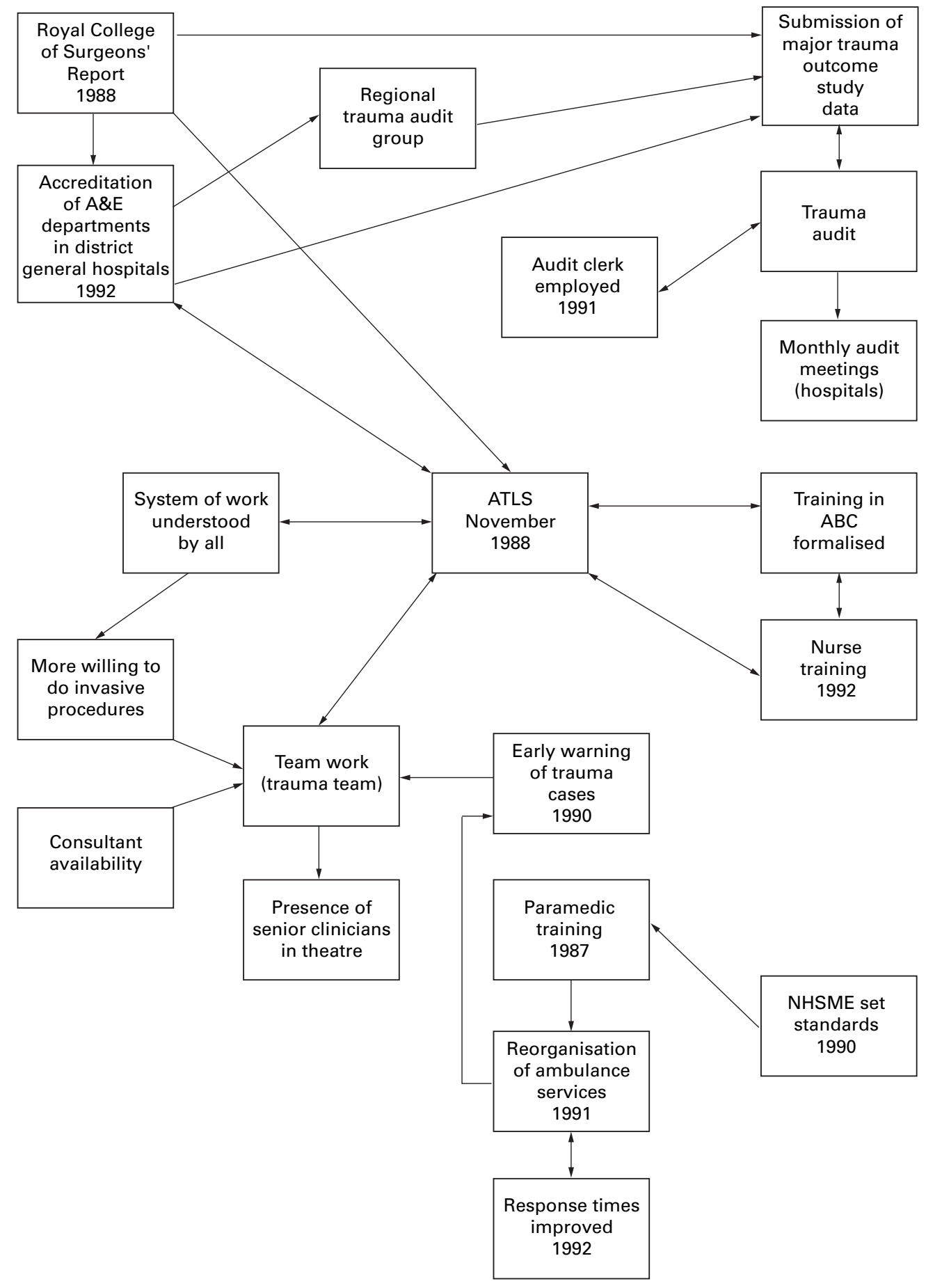

Figure 1 Linking the components of major trauma care.

\section{Discussion}

This study has determined the changes that have occurred in the management of serious injury in the UK over a critical five year period. These changes have led to documented improvements in survival in this particular patient group. The use of indepth qualitative interviews with key individuals, identified as having roles in the evolution of trauma services in the Leeds area during this time period, has allowed us to describe three categories of changenamely, policy, infrastructure, and philosophy of care. This strategic mix of components is likely to have parallels in attempts to improve outcomes in other areas aimed at producing a first class health service.

The main potential weakness of this study is the time interval between conducting interviews (beginning of 1996) and the period of study (1989-93). The interviewers were careful to ensure and keep reminding interviewees that they were being asked to deliberately reflect on what it was like to participate in the service after 1988 and draw out the differences between that experience and what it was like to participate up to 1993. The results of the study should, however, be interpreted cautiously as they were obtained retrospectively from a small 
number $(\mathrm{n}=10)$ of interviewees. Having determined that outcomes had improved, ${ }^{11}$ this was considered to be the most appropriate method for a study to describe the components of change. To obtain data as reliably as possible the interviewers repeatedly reminded interviewees that they should base their comments and reflections on the specific timescales.

The result is research that has attempted to outline the important components of an effective major trauma service. An obvious conclusion to draw is that an overall improvement in service quality is unlikely to be achieved as a result of investing in any single or small number of the items in figure 1. The observation that there are "no magic bullets"18 to the successful introduction of a change in professional behaviour is entirely consistent with this finding. The complex relationship of the several bullets of change in trauma management has been described (fig 1). Some of our specific findings merit further discussion, however.

REPORT OF THE ROYAL COLLEGE OF SURGEONS This report was recognised by clinical and managerial staff alike as being the forerunner to the development of local policy which would help to introduce better care. There was no doubt in the minds of respondents that a clear strategy set by a credible national body was important in aligning the perspectives and goals of members of the relevant professions. It is likely that the relatively public nature of the report and its open criticism of the management of major trauma had a significant impact on those shaping and delivering trauma services. It is this sort of impact which may in future be generated by new national bodies such as the National Institute for Clinical Excellence in the UK.

MAJOR TRAUMA OUTCOME STUDY

The major trauma outcome study provided a nationally driven framework for the collection, submission, and scrutiny of trauma survival data by hospitals, ${ }^{16}$ and, crucially, comparison with other hospitals. The existence of such a framework allowed common ground to be established between different centres and laid the foundation for a systematic process for clinical audit which was also replicated in each centre. Key benefits of this approach would include a common understanding among practitioners about what data actually mean. Additionally, standardisation of collection and definition of terms would be more likely to achieve credibility among clinicians. These factors, combined, make data more reliable to those clinicians who would wish to use them, which is a key step towards gaining acceptance and using audit results to drive quality improvement.

ATLS TRAINING

This training provided a common language for different professionals involved in the management of major trauma. Several of the respondents cited ATLS training as a useful "common language". Its importance lies both in provid- ing a widely known and understood framework for the early management of the critically ill patient and also in breaking interprofessional barriers, many of which are encoded in different professional attitudes, clinical terms, and codes of practice. ATLS is taught to any professional who is interested and involved in the management of trauma. Those who have been through the course, whether paramedic, nurse, or medical staff, will be able to discuss and identify with each others point of view using ATLS "speak".

\section{TEAMWORK}

The strong, if implicit, theme throughout this work is that of the role of clinical teams. Designated "trauma teams" where individuals carry a special bleep have developed as part of the approach to the management of trauma cases. These multiprofessional teams, united by ATLS principles and working in an area highlighted by the Royal College of Surgeons, will have had opportunities to develop rapidly. However, formal team development approaches and the development of specific clinical leaders was not necessarily a part of overall team development.

Clinician leaders were, however, important in the overall development of the philosophy of trauma care. In Leeds, one or two respected individuals who raised the profile of trauma management and placed it high in the priorities of those managing accident and emergency services helped to drive overall quality improvement. This model of the clinical leader or "local opinion leader" is consistent with the findings of others. ${ }^{19}$

CHANGE IN PHILOSOPHY OF CARE

The above factors, taken together, produce a change in philosophy. In the management of trauma this change would have meant a shift from dealing with patients, who happen to attend casualty after an incident of trauma, in a routine way to a more systematic approach, where:

- Severity of injury is defined

- Necessary steps to treat individuals are predefined

- A specific group of individuals from various backgrounds is identified as responsible for trauma management on any particularly day

- Impact of clinical actions is openly audited and debated.

ROLE OF PARAMEDICS

Many respondents made clear statements about the value of paramedic training in improving outcomes. A few respondents expressed reservations about the advisability of lengthy resuscitation at the accident site ("stay and play" versus "scoop and run"). This later view is consistent with the recent findings of the Health Technology Assessment report on paramedics. $^{20}$

\section{Conclusions}

Our findings can be related to models of strategic change such as that described initially by Pettigrew and Whipp, ${ }^{21}$ and adapted by 
Garside. ${ }^{22}$ In this model, Garside describes three important influences on strategic change-namely, process, context, and content. Our findings suggest that only the content and context of the change in trauma management can be clearly defined. The content has included targets for treatment times, specific protocols for management of specific clinical circumstances, and membership of trauma teams. The context can be divided into internal and external. Internally, the context in Leeds would have been governed by a series of young consultant appointments and enthusiastic paramedical and nursing clinicians all of whom were willing to engage in a common goal of improved care. Externally, the profile of trauma management was raised by bodies such as the NHS Executive and the Royal College of Surgeons. The process of change is far less clearly defined, and it is this subject which would merit further investigation. For example, we have not uncovered an individual who was formally accountable for shaping the change and channelling resources. No formal models of change management were used to produce the improvement in care and no stepwise or systematic process of implementation was used. The lack of such a systematic approach may have been counterbalanced by the existence of relatively powerful local clinicians who, implicitly, may well have brought about formal change management processes without recognising them as such.

The lesson for anyone wishing to engender quality improvement in their clinical service is far more complex than a simple box containing initiatives joined together by lines. Yet, it is this agenda which now faces NHS chief executives since the publication of the white paper, $A$ New $N H S,{ }^{23}$ and the recent guidance on NHS quality, $A$ First Class Service. ${ }^{24}$ A First Class Service in particular stresses the multiple factors which need to be assembled properly to achieve effective quality improvement. The government has detailed how the setting of national standards and nationally driven audit and feedback to clinicians will occur. It also recognises that lifelong learning, clinical leadership, and organisational development are important contributors to quality. Crucially, however, the detail on these necessary components of change is missing from $A$ First Class Service. ${ }^{24}$ It is, however, precisely these components which impact most on the work and learning environment. ${ }^{25}$ The New NHS suggests that getting all of these components in place, and some others (for example, evidence-based practice) are essential prerequisites for effective clinical governance. ${ }^{23}$

Our work with major trauma should allow policy makers, managers, and clinicians to reflect on some of the detail of $A$ First Class
Service which needs further exposition. The challenge posed for NHS chief executives is to encourage changes to happen to deliver the kind of outcome improvement seen in major trauma in Leeds. Our work suggests that this process will require a predetermined, or at least an emergent, strategic mixture of organisation and professional attitude changes in addition to the announced policy agenda.

We gratefully thank Mr Peter Millner for his help in our research and for his comment on a draft of this manuscript. We especially thank all our interviewees.

1 Royal College of Surgeons of England. Report of the working party on the management of patients with major injuries. London: RCS, 1988

2 Bangdiwala SI, Anzola-Perez E. The incidence of injuries in young people: II. Log-linear multivariable models for risk young people: II. Log-linear multivariable models for risk Venezuela. Int $\mathcal{F}$ Epidemiol 1990;19:125-32.

3 Silva JF. Review of patients with multiple injuries treated at University Hospital, Kuala Lumpur. F Trauma 1984;24: $526-31$

4 National Safety Council. Accident facts, 1991. Chicago, National Safety Council 1991;12:6-7.

5 Department of Health. Mortality statistics by cause; England and Wales 1995. London: HMSO, 1996.

6 British Orthopaedic Association. Report of the trauma committee of the British Orthopaedic Association; the management of skeletal trauma in the United Kingdom. London: BOA, 1992.

7 Anderson ID, Woodford M, deDombal FT, et al. Retrospecive study of 1000 deaths from injury in England and Wales. BMF 1988;296:1305-8.

8 Department of Health. Health of the nation: a strategy for health in England. London: HMSO, 1992.

9 Department of Health. Our healthier nation: a contract for health. London: The Stationary Office, 1998.

10 Airey CM, Franks AJ. Major trauma workload within an English Health Region. Injury 1995;26:25-31.

11 Burdette-Smith P, Airey CM, Franks AJ. Improvements in trauma survival in Leeds. Injury 1995;26:455-62.

12 Spence MT, Redmond AD, Edwards JD. Trauma audit: the Spence MT, Redmond AD, Edwards JD. Tra
use of TRISS. Health Trends 1988;20:94-7.

13 Roberts I, Campbell F, Hollis S, et al. Reducing accident death rates in children and young adults: the contribution of hospital care. BMF 1996;313:1239-41.

14 Britten N, Qualitative interviews in medical research. BMF 1995;311:251-3

15 Patton MQ, Designing qualitative studies. In: Qualitative evaluation and research methods. London: Sage, 1990.

16 Yates DW, Woodford M, Hollis S. Preliminary analysis of the care of injured patients in 33 British hospitals: the first report of the United Kingdom major trauma outcome study. BMF 1992;305:737-40.

17 Department of Health. The modern ambulance service, report by working group to chief executive. London: NHSME good by working group to chief

18 Oxman A. No magic bullets. A systematic review of 102 trials of interventions to help healthcare professionals deliver services more effectively or efficiently. London: North East Thames regional Health Authority, 1994.

19 Lomas J, Enkin M, Anderson G, et al. Opinion leaders versus audit and feedback to implement practice guidelines. ҰAMA 1991;265:2202-7.

20 Nicholl J, Hughes S, Dixon S, et al. The costs and benefits of paramedic skills in pre-hospital trauma care. Health Technol Assessment 1998;2:17.

21 Pettigrew AM, Whipp R. Managing change for competitive success. Oxford: Blackwell, 1991.

22 Garside P. Organisational context for quality: lessons from the fields of organisational development and change management. Quality in Healthcare 1998; 7:(suppl)8-15.

23 Department of Health. The new NHS: modern, dependable. London: DoH, 1998.

24 Department of Health. A first class service. London: DoH, 1998.

25 Mittman BS, Tonesk X, Jacobson PD. Implementing clinical practice guidelines: social influence strategies and practitioner behaviour change. Quality Review Bulletin 1992;18:413-22. 